\title{
Dasatinib enhances tumor growth in gemcitabine-resistant orthotopic bladder cancer xenografts
}

Stefan Vallo ${ }^{1,2}$, Martin Michaelis ${ }^{3}$, Kilian M. Gust $^{2,4}$, Peter C. Black ${ }^{4}$, Florian Rothweiler ${ }^{1}$, Hans-Michael Kvasnicka ${ }^{5}$, Roman A. Blaheta ${ }^{2}$, Maximilian P. Brandt ${ }^{2}$, Felix Wezel ${ }^{6}$, Axel Haferkamp ${ }^{2}$ and Jindrich Cinatl Jr..$^{*}$

\begin{abstract}
Background: Systemic chemotherapy with gemcitabine and cisplatin is standard of care for patients with metastatic urothelial bladder cancer. However, resistance formation is common after initial response. The protein Src is known as a proto-oncogene, which is overexpressed in various human cancers. Since there are controversial reports about the role of Src in bladder cancer, we evaluated the efficacy of the Src kinase inhibitor dasatinib in the urothelial bladder cancer cell line RT112 and its gemcitabine-resistant sub-line RT112 $\mathrm{GEMCl}^{20}$ in vitro and in vivo.
\end{abstract}

Methods: RT112 urothelial cancer cells were adapted to growth in the presence of $20 \mathrm{ng} / \mathrm{ml}$ gemcitabine $\left(\mathrm{RT} 112^{\mathrm{r}} \mathrm{GEMCl}^{20}\right.$ ) by continuous cultivation at increasing drug concentrations. Cell viability was determined by MTT assay, cell growth kinetics were determined by cell count, protein levels were measured by western blot, and cell migration was evaluated by scratch assays. In vivo tumor growth was tested in a murine orthotopic xenograft model using bioluminescent imaging.

Results: Dasatinib exerted similar effects on Src signaling in RT112 and RT112r GEMCl ${ }^{20}$ cells but RT112 $2^{r} \mathrm{GEMCl}^{20}$ cells were less sensitive to dasatinib-induced anti-cancer effects (half maximal inhibitory concentration $\left(\mathrm{IC}_{50}\right.$ ) of dasatinib in RT112 cells: $349.2 \pm 67.2$ nM; IC 50 of dasatinib in RT112 ${ }^{r} \mathrm{GMCl}^{20}$ cells: $1081.1 \pm 239.2 \mathrm{nM}$ ). Dasatinib inhibited migration of chemo-naive and gemcitabine-resistant cells. Most strikingly, dasatinib treatment reduced RT112 tumor growth and muscle invasion in orthotopic xenografts, while it was associated with increased size and muscle-invasive growth in $\mathrm{RT} 112^{\mathrm{r}} \mathrm{GEMCl}^{20}$ tumors.

Conclusion: Dasatinib should be considered with care for the treatment of urothelial cancer, in particular for therapyrefractory cases.

Keywords: Acquired resistance, Cancer cell line collection, Dasatinib, Gemcitabine, Orthotopic xenograft model, Urothelial bladder cancer

\section{Background}

Bladder cancer is the second most common cancer of the genitourinary tract. First-line therapy regimens for metastatic disease include gemcitabine and cisplatin (GC) as standard of care resulting in response rates of 40-70\%. However, resistance acquisition is common and the

\footnotetext{
*Correspondence: Cinatl@em.uni-frankfurt.de

${ }^{1}$ Institute of Medical Virology, Goethe University Frankfurt,

Paul-Ehrlich-Str. 40, 60596 Frankfurt am Main, Germany

Full list of author information is available at the end of the article
}

median survival is unsatisfactory being $12-14$ months [1, 2]. Effective second-line therapies are missing [3, 4].

The c-Src proto-oncogene has been strongly implicated in the development, growth, progression, and metastasis of a number of human cancers including those of colon, breast, pancreas, and brain $[5,6]$. Several clinical trials showed antitumoral activity of Src family inhibitor dasatinib in different cancer entities $[7,8]$. The role of Src kinase as drug target in bladder cancer is controversial. Src inhibition caused anti-cancer effects in some bladder cancer cell lines (including RT112) and animal models [9, 
10]. In other studies, however, Src inhibition increased bladder cancer cell migration and metastasis formation $[11,12]$. A recently published phase II trial did not demonstrate clinical benefit of single-agent dasatinib in unselected patients with muscle-invasive urothelial carcinoma of the bladder [13].

Here, we investigated the effects of dasatinib on RT112 urothelial bladder cancer cells and RT112 cells with acquired resistance to gemcitabine $\left(\mathrm{RT} 112^{\mathrm{r}} \mathrm{GEMCI}^{20}\right)$ in cell culture and in an orthotopic xenograft model.

\section{Methods}

\section{Drugs}

Gemcitabine $\left(\mathrm{Gemzar}^{\circledR}\right)$ was obtained from Lilly (Indianapolis, IN, USA). Dasatinib was obtained from Absource Diagnostics (München, Germany).

\section{Cell lines and lentiviral transduction}

RT112 cells were obtained from the American Type Culture Collection (Manassas, VA, USA). Cells were grown in Iscove's modified Dulbecco's medium supplemented with $10 \%$ fetal calf serum (FCS, Gibco, Karlsruhe, Germany). RT112 cells were adapted to growth in presence of $20 \mathrm{ng} / \mathrm{ml}$ gemcitabine by continuous cultivation in the presence of increasing drug concentrations as previously described [14] resulting in the gemcitabine-resistant subline RT112 ${ }^{\mathrm{r}} \mathrm{GEMCI}^{20}$. For in vivo studies, RT112 and RT112 ${ }^{\mathrm{r}} \mathrm{GEMCI}^{20}$ cell lines underwent transduction with a lentiviral construct carrying the luciferase firefly gene for in vivo imaging resulting in cell lines RT112luc and RT112 ${ }^{\mathrm{r}} \mathrm{GEMCI}^{20}$ luc. The luciferase plasmid contained a blasticidin-resistance gene enabling positive selection with $10 \mathrm{mg} / \mathrm{ml}$ blasticidin (Life Technologies $\mathrm{GmbH}$, Darmstadt, Germany). Cell lines were controlled for in vitro luciferase activity and cell number was correlated with bioluminescence using the Xenogen IVIS Spectrum (Caliper Lifesciences, Hopkinton, MA, USA) as previously described [15].

\section{Viability assay}

Cell viability was tested by 3-(4,5-dimethylthiazol-2-yl)2,5-diphenyltetrazolium bromide (MTT) dye reduction assay after $120 \mathrm{~h}$ incubation modified as described before [16]. All experiments were performed at least in triplicate.

\section{Cell proliferation}

At day 0, 4000 cells $/ \mathrm{ml}$ were plated in culture flasks. Cell numbers were determined every $24 \mathrm{~h}$ for 6 consecutive days using the automated cell counter Countess ${ }^{\circledR}$
(Life Technologies $\mathrm{GmbH}$ ) after trypan blue staining. Doubling time (DT) was calculated using the formula $\mathrm{DT}=$ culture time/cell doubling. Cell doubling $=\ln (\mathrm{Nf} /$ $\mathrm{Ni} / \mathrm{ln} 2$, where Ni represents seeded cells number and $\mathrm{Nf}$ the harvested cells number [17]. All experiments were performed at least in triplicate.

\section{Western blot}

Cells were lysed in Triton X sample buffer and separated by sodium dodecyl sulfate polyacrylamide gel electrophoresis (SDS-PAGE). Proteins were detected using specific antibodies against $\beta$-actin (\#A5441, Sigma-Aldrich, St. Louis, MO, USA), Src (\#2123, Cell Signaling, Cambridge, UK), phosphorylated Src (Tyr416, \#2101, Cell Signaling), Akt (\#9272, Cell Signaling), and phosphorylated Akt (Thr308, \#2965, Cell Signaling and Ser473, \#04-736, EMD-Millipore, Billerica, MA, USA). Protein bands were visualized by enhanced chemiluminescence using a commercially available kit (GE Healthcare, Little Chalfont, UK). Pixel density of western blots is given in percentage compared to untreated cell line (100\%). All experiments were performed at least in triplicate.

\section{Wound healing migration assay}

RT112 or RT112 $2^{\mathrm{r}} \mathrm{GEMCI}^{20}$ cells were plated onto six-well plates and allowed to form a confluent monolayer. The cell monolayer was then scratched in a straight line to make a 'scratch wound' with a $0.2 \mathrm{ml}$ pipette tip and the cell debris was removed by washing the cells with phosphate-buffered saline. Images of the closure of the scratch were captured at 0,6, and $24 \mathrm{~h}$. Quantification of wound repair was obtained from six measurements of every treatment from three independent experiments.

\section{Ethics statement}

All animal procedures were performed according to the guidelines of the Canadian Council on Animal Care and approved by the Institutional Review Board of the University of British Columbia (approval \#A10-0295).

\section{Intramuscular orthotopic xenograft murine model}

Animal experiments were performed as described previously $[15,18]$. Mice were subdivided into four treatment arms: RT112luc control treatment $(\mathrm{n}=15)$, RT112luc dasatinib treatment $(\mathrm{n}=15)$, $\mathrm{RT}_{11} 2^{\mathrm{r}} \mathrm{GEMCI}^{20}$ luc control treatment $(\mathrm{n}=15)$, and $\mathrm{RT} 112^{\mathrm{r}} \mathrm{GEMCI}^{20}$ luc dasatinib treatment $(\mathrm{n}=14)$. Six-week-old male nude mice (Harlan Laboratories, Indianapolis, IN, USA) were anesthetized with isoflurane (2 Vol. \%) and analgesia was provided by subcutaneous injection with buprenorphine 
and meloxicam (Boehringer Ingelheim, Burlington, $\mathrm{ON}$, Canada). After disinfection of the abdominal wall with chlorhexidine, a low transverse laparotomy was made and the urinary bladder was extracorporealized. $50 \mu \mathrm{l}$ of a cell suspension containing $5 \times 10^{5}$ cells were directly injected into the bladder wall. The incision was closed with suture. Bioluminescence was used to quantify tumor burden and was measured on the xenogen IVIS spectrum imaging system after intraperitoneal injection of $200 \mu \mathrm{g} / \mathrm{kg}$ luciferin (Caliper Lifesciences). Images were taken at 10 and $14 \mathrm{~min}$ after luciferin injection and the average counts were used for statistical analysis. Evaluation of bioluminescence in this orthotopic model showed that $10 \times 10^{8}$ photons/s correlate to $10 \mathrm{~mm}^{3}$ tumor volume [19]. Bioluminescence imaging was performed on day 5 after tumor inoculation and mice were divided into equal treatment groups based on tumor burden. Treatment started the following day and imaging was repeated every 4 days. Necropsy was performed after 4 weeks. Dasatinib was administered by oral gavage with an in vivo relevant dose of $20 \mathrm{mg} / \mathrm{kg}$ body weight (BW) twice daily [20] in sodium citrate/citric acid (Sigma-Aldrich, St. Louis, MO, USA). Vehicle treatment was prepared and administered in an identical manner, but without dasatinib. All experiments were performed at least in triplicate.

\section{Haematoxylin and eosin staining (H\&E)}

All samples were fixed in buffered $4 \%$ formalin (pH7.4) and embedded in paraffin. We used standard procedures for deparaffinization and rehydration. Slides were cut at a microtome into $3 \mu \mathrm{m}$ slices. H\&E staining were performed according to standard.

\section{Statistical analysis}

Results are expressed as mean \pm standard deviation (SD) of at least three independent experiments. For statistical analysis student's $t$ test, analysis of variance (ANOVA), and Student-Newman-Keuls-Test were performed whenever applicable. Significance was defined at values of $\mathrm{p} \leq 0.05$.

\section{Results}

\section{Growth characteristics and sensitivity to gemcitabine} of RT112 and RT112 ${ }^{\mathrm{r}} \mathrm{GEMCl}^{20}$ cells

RT112 and RT112 ${ }^{\mathrm{r}} \mathrm{GEMCI}^{20}$ cells showed similar growth kinetics with doubling times of $23.28 \pm 2.88 \mathrm{~h}$ in RT112 cells and $25.2 \pm 3.12 \mathrm{~h}$ in $\mathrm{RT}^{2} 12^{\mathrm{r}} \mathrm{GEMCI}^{20}$ cells. Transduction with the luciferase plasmid, which is needed to monitor in vivo tumor growth, did not alter cell growth kinetics (doubling time RT112luc: $24.72 \pm 5.04 \mathrm{~h}$; doubling time RT112 $2^{\mathrm{r}} \mathrm{GEMCI}^{20}$ luc: $27.36 \pm 3.6$ h) (Fig. 1a; Table 1). RT112 ${ }^{\mathrm{r}} \mathrm{GEMCI}^{20}$ cells $\left(\mathrm{IC}_{50}=125.40 \pm 29.78 \mathrm{ng} / \mathrm{ml}\right)$ displayed a 77 -fold increased resistance to gemcitabine compared to parental RT112 cells $\left(\mathrm{IC}_{50}=1.63 \pm 0.55 \mathrm{ng} / \mathrm{ml}\right)$. There was a similar sensitivity to gemcitabine in the luciferasetransduced cell lines RT112luc and RT112 ${ }^{\mathrm{r}} \mathrm{GEMCI}^{20}$ luc compared to RT112 and RT112 ${ }^{\mathrm{r}} \mathrm{GEMCI}^{20}$ [RT112luc $\left(\mathrm{IC}_{50}: 1.94 \pm 0.24\right)$ and $\mathrm{RT} 112^{\mathrm{r}} \mathrm{GEMCI}^{20} \mathrm{luc}\left(\mathrm{IC}_{50}\right.$ : $114.39 \pm 14.52)]$ (Table 1).

\section{Growth characteristics of RT112luc and RT112 ${ }^{\mathrm{r}} \mathrm{GEMCl}{ }^{20}$ luc tumors in vivo}

In vivo, growth of RT112luc and RT112 ${ }^{\mathrm{r}} \mathrm{GEMCI}^{20}$ luc tumors was investigated in an established murine orthotopic xenograft model $[15,18,19,21]$. RT112 ${ }^{\mathrm{r}}$ GEMCI-

${ }^{20}$ luc cells were used for the first time in this orthotopic model. Nude mice received either $5 \times 10^{5}$ RT112luc or RT112 ${ }^{\mathrm{r}} \mathrm{GEMCI}^{20}$ luc cells directly injected into the bladder wall. Tumor take rates were $90 \%$ (27 out of 30 animals) for RT112luc cells and $100 \%$ (30 out of 30 animals) for RT112 ${ }^{\mathrm{r}} \mathrm{GEMCI}^{20}$ luc cells. RT112 ${ }^{\mathrm{r}} \mathrm{GEMCI}^{20}$ luc xenografts grew substantially slower than RT112luc xenografts resulting in a 6-fold smaller average tumor volume at day $25(\mathrm{p}<0.0001)$ (Fig. 1b).

\section{In vitro effects of dasatinib on $\mathrm{RT} 112$ and $\mathrm{RT} 112^{\mathrm{r}} \mathrm{GEMCl}{ }^{20}$ \\ cells}

RT112 ${ }^{\mathrm{r}}$ EEMCI $^{20}$ cells $\left(\mathrm{IC}_{50}: 1081.1 \pm 239.2 \mathrm{nM}\right)$ showed a 3.1-fold decreased sensitivity to dasatinib compared to parental RT112 cells $\left(\mathrm{IC}_{50}: 349.2 \pm 67.2 \mathrm{nM}\right)$. The concentration-dependent drug response from a representative experiment is shown in Fig. 1c.

In cell culture, dasatinib caused in RT112 and in RT112 ${ }^{\mathrm{r}} \mathrm{GEMCI}^{20}$ cells a dose-dependent reduction of Src phosphorylation. Phosphorylation of Akt (Thr308) was also reduced in both cell lines with a stronger inhibition in the chemo-naive cell line. No inhibition of pAkt (Ser473) was detected (Fig. 2a, b).

Since Src inhibition was described to increase migration in urothelial cancer [12], we evaluated migratory behavior using a wound healing scratch assay in RT112 and $\mathrm{RT} 112^{\mathrm{r}} \mathrm{GEMCI}^{20}$ cells with and without dasatinib treatment. Results indicated a similar time-dependent migration inhibition in response to dasatinib in RT112 and $\mathrm{RT} 112^{\mathrm{r}} \mathrm{GEMCI}^{20}$ cells resulting in $>60 \%$ inhibition of migration in both cell lines relative to untreated control (p < 0.0001) (Fig. 2c, d). 

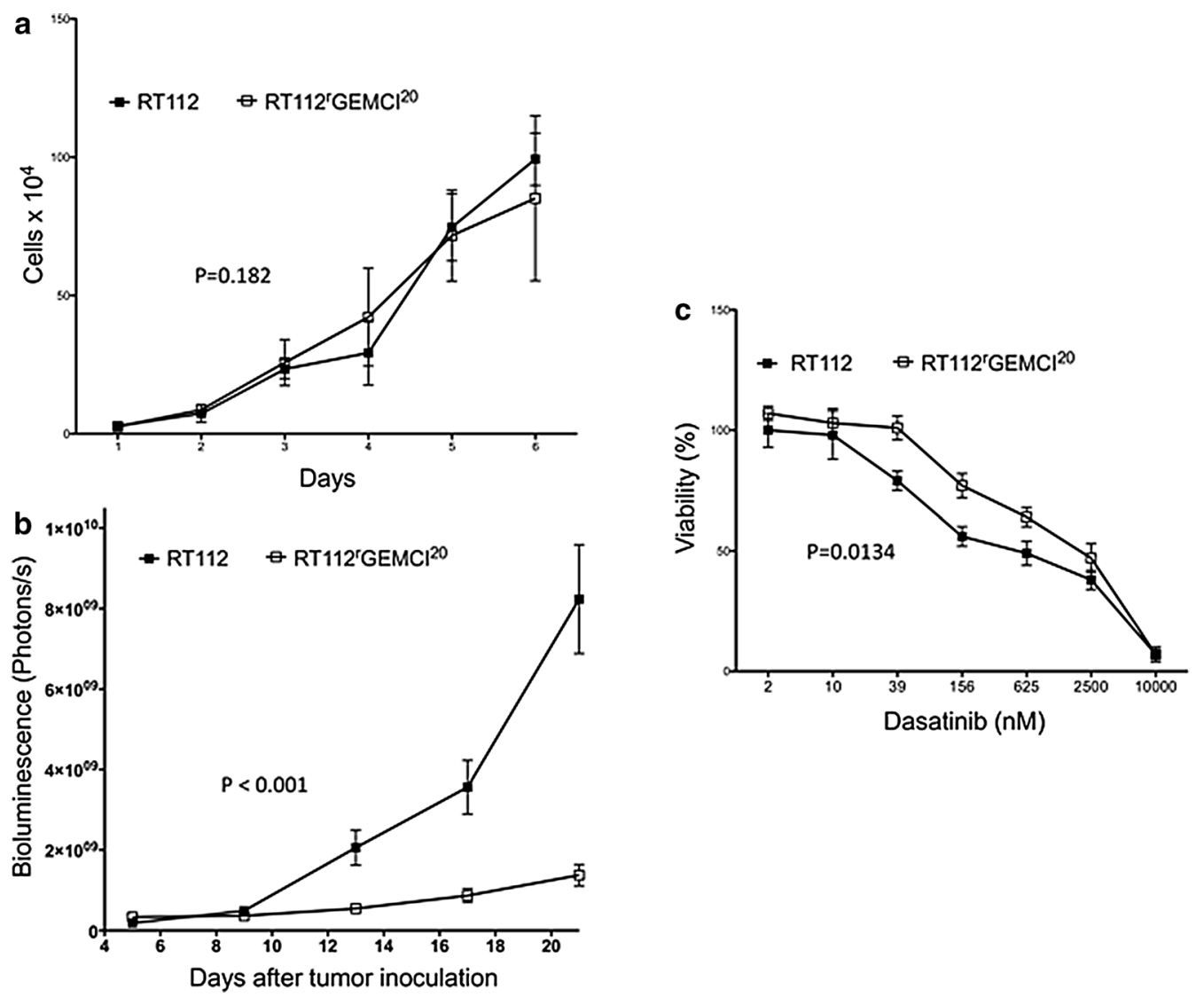

Fig. 1 a Growth kinetics of the urothelial cancer cell line RT112 and its gemcitabine-resistant sub-line RT112 $2^{r} G E M C{ }^{20}$ in cell culture. On day 0 , both cell lines started with 4000 cells per milliliter. $\mathbf{b}$ In vivo growth kinetics of RT112luc and RT112 ${ }^{r} G E M C{ }^{20}$ luc tumors in an orthotopic nu/nu mouse xenograft model as determined by bioluminescence. $10 \times 10^{8}$ photons $/ \mathrm{s}$ correlate to $10 \mathrm{~mm}^{3}$ tumor volume (21). c Concentration-dependent effects of dasatinib on the viability of the urothelial cancer cell line RT1 12 and its gemcitabine-resistant sub-line RT1 $12^{r} G_{E M C l}{ }^{20}$ as indicated by MTT assay after $120 \mathrm{~h}$ of incubation

Table 1 Comparison of growth kinetics (doubling time) of RT112, RT112 ${ }^{\mathrm{G} E M C I^{20}}$, RT112luc, and RT112 ${ }^{\mathrm{G}} \mathrm{GEM}$ $\mathrm{Cl}^{20}$ luc cell lines and cell viability $\left(\mathrm{IC}_{50}\right)$ after treatment with gemcitabine

\begin{tabular}{|c|c|c|}
\hline Cell line & Doubling time (h) & $I C_{50}(\mathrm{ng} / \mathrm{ml})$ \\
\hline RT112 & $23.28 \pm 2.88$ & $1.63 \pm 0.55$ \\
\hline $\mathrm{RT} 112^{\mathrm{r}} \mathrm{GEMCl} \mathrm{C}^{20}$ & $25.2 \pm 3.12$ & $125.40 \pm 29.78$ \\
\hline RT112luc & $24.72 \pm 5.04$ & $1.94 \pm 0.24$ \\
\hline RT112 GEMCl ${ }^{20}$ luc & $27.36 \pm 3.6$ & $114.39 \pm 14.52$ \\
\hline
\end{tabular}

Effects of dasatinib treatment in RT112luc and $\mathrm{RT} 112^{\mathrm{r}} \mathrm{GEMCl}{ }^{20}$ luc xenografts

Dasatinib treatment using $20 \mathrm{mg} / \mathrm{kg}$ twice daily [20] caused a reduction of RT112luc xenograft size by $39 \%$ $(\mathrm{p}=0.036)$ relative to untreated control at day 25 . In contrast, dasatinib treatment induced a 4-fold increase in $\mathrm{RT} 112^{\mathrm{r}} \mathrm{GEMCI}{ }^{20}$ luc tumor size compared to vehicle treated $\mathrm{RT} 112^{\mathrm{r}} \mathrm{GEMCI}^{20}$ luc xenografts at day 25 (p $<0.001$ ) (Fig. 3).

Tumors were sampled and $\mathrm{H} \& \mathrm{E}$ staining was performed at day 25. Untreated RT112luc tumors displayed muscle-invasive growth (pT2) (Fig. 4a). In contrast, no signs of muscle-invasive growth (pT1) were detected in dasatinib-treated RT112luc tumors (Fig. 4b). The opposite pattern was observed in $\mathrm{RT} 112^{\mathrm{r}} \mathrm{GEMCI}^{20}$ luc tumors. Untreated $\mathrm{RT} 112^{\mathrm{r}} \mathrm{GEMCI}^{20}$ luc tumors did not show muscle-invasive growth (pT1) (Fig. 4c), while dasatinibtreated RT112 ${ }^{\mathrm{r}} \mathrm{GEMCI}^{20}$ luc xenografts displayed muscle invasive growth (pT2) ( $<<0.001)$. In dasatinib-treated RT1 $12^{\mathrm{r}} \mathrm{GEMCI}^{20}$ luc xenografts, the bladder muscle was completely infiltrated by the tumor, and the bladder wall was not clearly visible anymore (Fig. 4 d). 


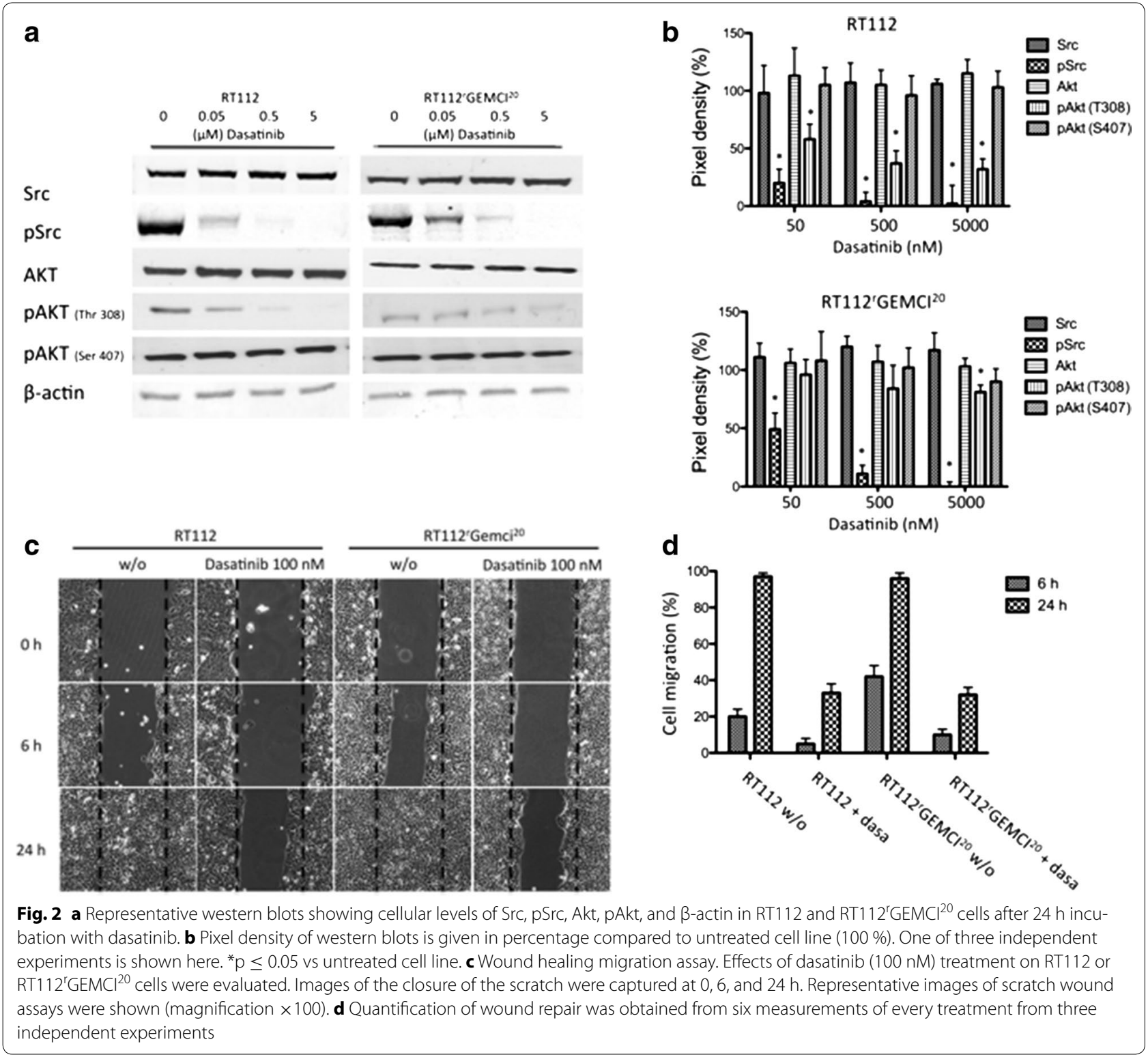

\section{Discussion}

In this study, we compared the effects of the Src inhibitor dasatinib on the urothelial cancer cell line RT112 and its gemcitabine-resistant sub-line $\mathrm{RT} 112^{\mathrm{r}} \mathrm{GEMCI}^{20}$ in cell culture and in an orthotopic bladder cancer xenograft model in mice.

In cell culture, both cell lines displayed similar growth kinetics. Dasatinib inhibited Src phosphorylation in
RT112 and $\mathrm{RT}_{112}{ }^{\mathrm{r}} \mathrm{GEMCI}^{20}$ cells at low nanomolar concentrations similar to those that had already been described to affect Src phosphorylation [9]. While dasatinib had previously been shown to interfere with the phosphorylation of Akt (Thr308 and Ser473) in squamous cell lung cancer [22], we only detected inhibition of phosphorylation of Akt (Thr308). The reasons for this may be the consequence of cell type-specific differences 


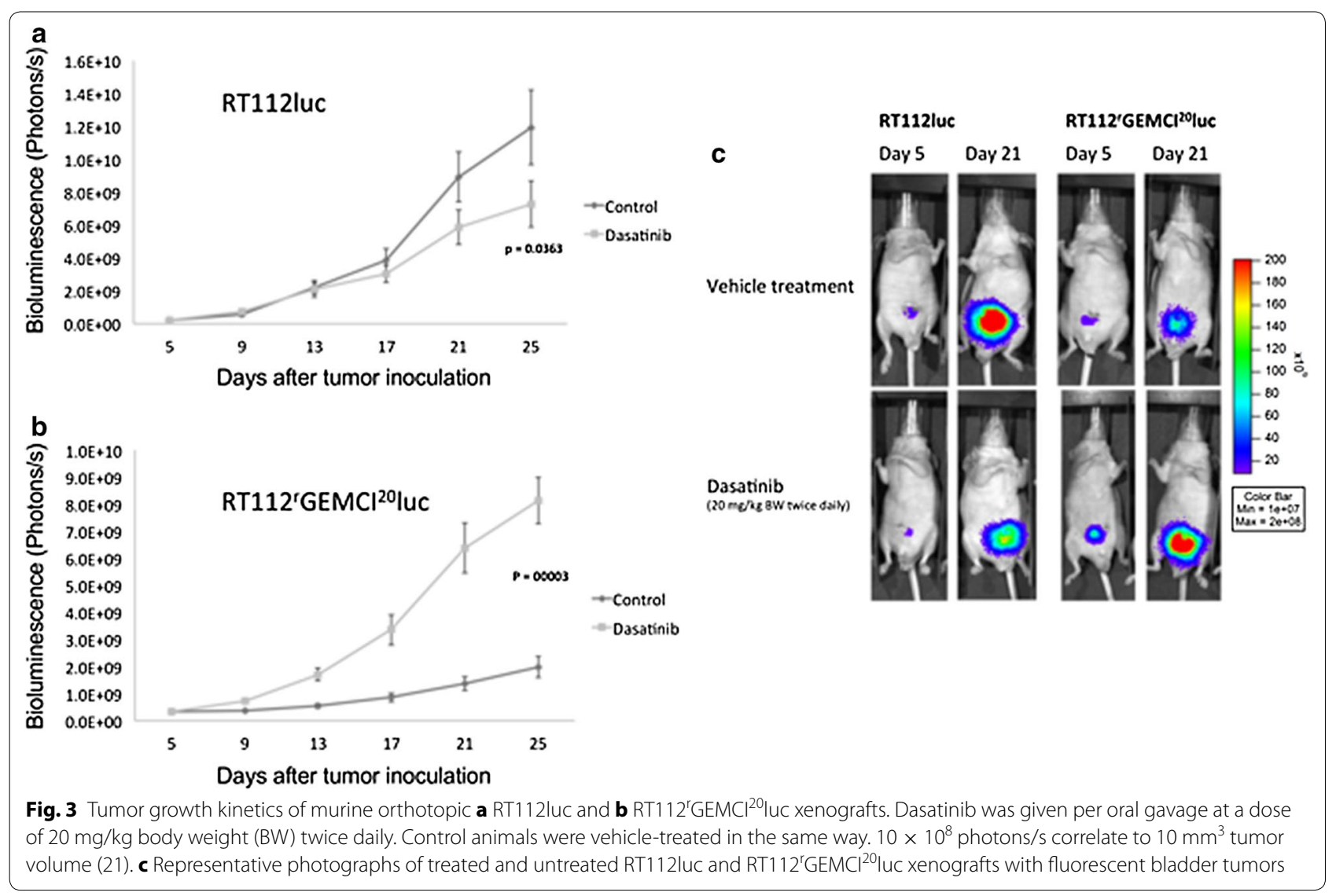

between the investigated models. Although dasatinib exerted similar effects on Src signaling in RT112 and RT $112^{\mathrm{r}} \mathrm{GEMCI}^{20}$ cells, its effects on cell viability differed between the two cell lines. The effective concentrations of dasatinib in RT112 cells ( $\mathrm{IC}_{50}$ of $349.2 \pm 67.2 \mathrm{nM}$ ) were in the range of those previously described for the treatment of urothelial cancer cells [9]. However, in $\mathrm{RT} 112^{\mathrm{r}} \mathrm{GEMCI}^{20}$ cells the $\mathrm{IC}_{50}$ value was about 3 -fold higher $(1081.1 \pm 239.2 \mathrm{nM})$. This suggests that RT112 ${ }^{\mathrm{r}} \mathrm{GEMCI}^{20}$ cells have acquired resistance mechanisms that interfere with antitumoral effects of dasatinib downstream of Src signaling. In accordance, dasatinib treatment resulted in reduced inhibition of the phosphorylation of the Src downstream kinase Akt (Thr 308) in RT112 ${ }^{\mathrm{r}} \mathrm{GEMCI}^{20}$ cells compared to RT112 cells.

In nude mice, $\mathrm{RT} 112^{\mathrm{r}} \mathrm{GEMCI}^{20}$ luc cells formed about 6-fold smaller tumors than RT112luc cells. The reasons for this remain unclear. However, it is known that different cell lines may differ in their interaction with the tissue environment in animal models resulting in discrepancies in the growth kinetics $[23,24]$.

The most striking differences were found after oral dasatinib treatment of mice bearing orthotopic
RT112luc or RT112 $2^{\mathrm{r}} \mathrm{GEMCI}^{20}$ luc xenografts. Dasatinib treatment of RT112luc bladder tumors resulted in a significant reduction of tumor size relative to untreated control. In contrast, dasatinib treatment of RT $112^{\mathrm{r}} \mathrm{GEM}$ $\mathrm{CI}^{20}$ luc bladder tumors resulted in a dramatic increase of tumor growth. In addition, the dasatinib treatment prevented muscle-invasive growth of RT112luc xenografts, but strongly induced muscle-invasive growth of $\mathrm{RT} 112^{\mathrm{r}} \mathrm{GEMCI}^{20}$ luc xenografts. The mechanistic reasons underlying this discrepancy remain elusive. Wu et al. [11] had reported that loss of Src increases metastasis formation in a bladder cancer model. Similar to this report, Thomas et al. [12] showed that Src enhances urothelial cancer cell migration and metastasis formation. However, dasatinib inhibited RT112 and $\mathrm{RT}_{112}{ }^{\mathrm{r}} \mathrm{GEMCI}^{20}$ cell migration in a similar manner, similarly to other studies that reported on the effects of Src inhibition on cancer cell migration in models from different cancer entities [25-28]. Therefore, it seems unlikely that the dasatinib-induced increased invasive growth of $\mathrm{RT} 112^{\mathrm{r}} \mathrm{GEMCI}^{20}$ luc cells in the xenograft model may be caused by dasatinib-induced enhanced RT $112{ }^{\mathrm{r}} \mathrm{GEMCI}^{20}$ luc cell migration. 

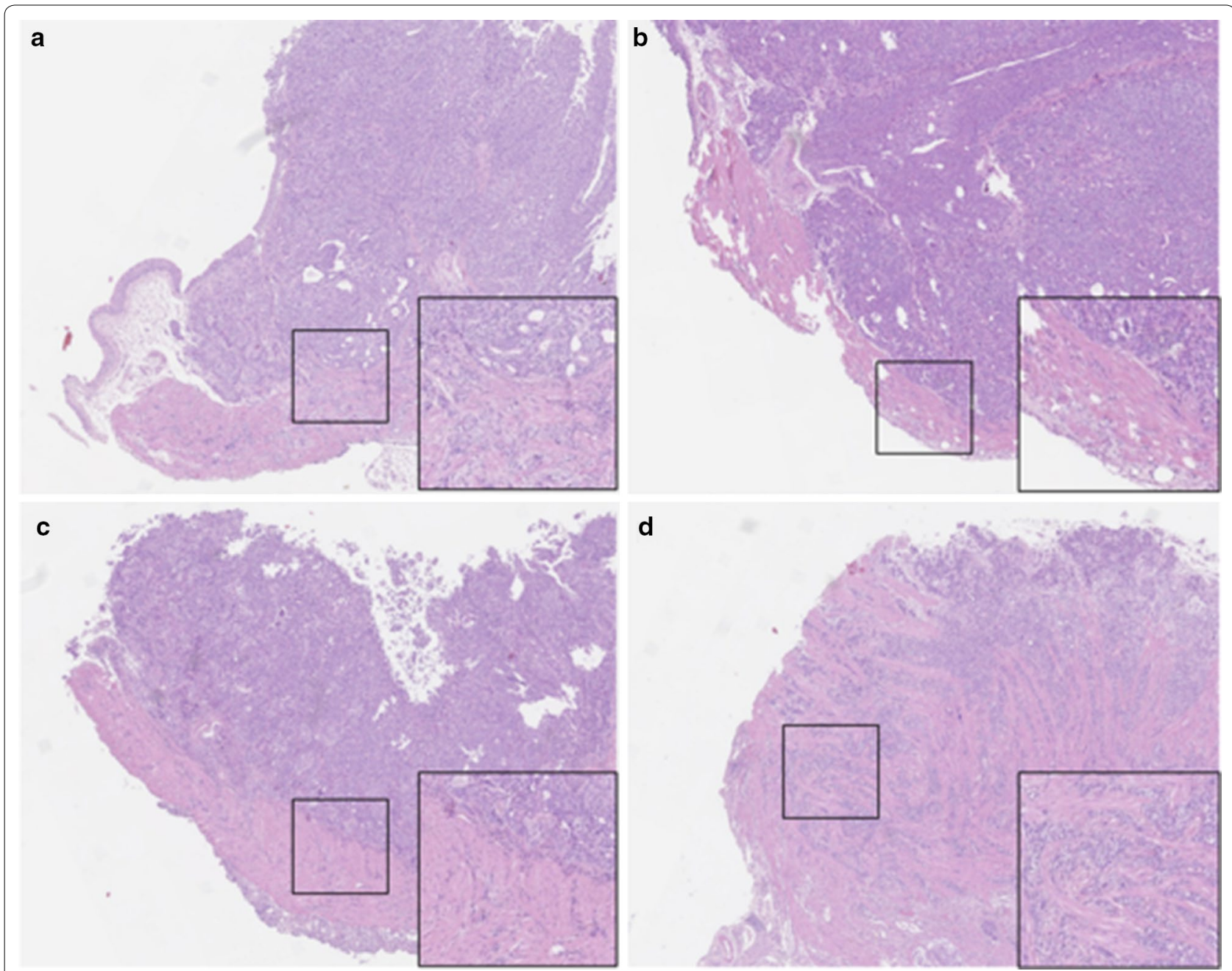

Fig. 4 H\&E staining of four representative tumors (magnification $\times 5$ ). a RT112luc xenograft from a vehicle-treated mouse. b RT112luc xenograft

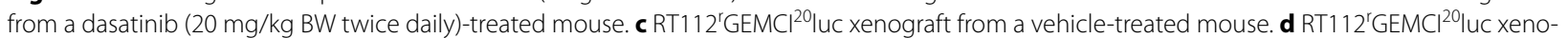
graft from a dasatinib (20 mg/kg BW twice daily)-treated mouse

\section{Conclusions}

We present the first study that investigated the effects of dasatinib on urothelial cancer cells with acquired resistance to gemcitabine. In cell culture, gemcitabine-resistant RT112 cells were less sensitive to dasatinib than parental RT112 cells. Notably, parental RT112 cells and gemcitabineresistant RT112 cells displayed an unexpected opposite response to dasatinib in an orthotopic xenograft model in mice. While dasatinib inhibited tumor growth and muscle invasion by parental RT112 cells, it increased tumor growth and muscle invasion by gemcitabine-resistant RT112 cells. Thus, our data do not generally support the use of dasatinib for the treatment of urothelial cancer, in particular not for therapy-refractory cases after first-line chemotherapy with gemcitabine. However, further studies will need to show whether similar effects are obtained in additional models of (acquired gemcitabine resistance in) urothelial cancer. If such studies suggested that some urothelial cancer diseases may benefit from dasatinib therapy, biomarkers would need to be identified that enable the prediction of the response of individual urothelial cancer diseases to dasatinib.

\section{Abbreviations}

MTT: 3-(4,5-dimethylthiazol-2-yl)-2,5-diphenyltetrazolium bromide; IC 50 : half maximal inhibitory concentration; GC: gemcitabine and cisplatin; DT: doubling time; H\&E: haematoxylin and eosin staining; SD: standard deviation; ANOVA: analysis of variance.

\section{Authors' contributions}

SV, KG: data collection, project development, data analysis, manuscript writing MM, PB, JC: project development, data analysis, manuscript writing. FR: data collection, data analysis. HK: data collection, manuscript writing. RB, MB, FW: data analysis, manuscript writing. AH: data analysis, project development. All authors read and approved the final manuscript. 


\begin{abstract}
Author details
${ }^{1}$ Institute of Medical Virology, Goethe University Frankfurt, Paul-Ehrlich-Str. 40, 60596 Frankfurt am Main, Germany. ${ }^{2}$ Department of Urology, Goethe University Frankfurt, Frankfurt, Germany. ${ }^{3}$ Centre for Molecular Processing and School of Biosciences, University of Kent, Canterbury, UK. ${ }^{4}$ Department of Urologic Sciences, Vancouver Prostate Centre, University of British Columbia, Vancouver, Canada. ${ }^{5}$ Dr. Senckenberg Institute of Pathology, Goethe University Frankfurt, Frankfurt am Main, Germany. ${ }^{6}$ Department of Urology, University Hospital Ulm, Ulm, Germany.
\end{abstract}

\section{Acknowledgements}

The work was supported by the charity Hilfe für krebskranke Kinder Frankfurt e.V., its trust Frankfurter Stiftung für krebskranke Kinder, the Patenschaftsmodell program of the University Hospital Frankfurt and the Kent Cancer Trust.

\section{Competing interests}

The authors declare that they have no competing interests.

\section{Availability of data and materials}

All data and further information about "Methods" section are available via the corresponding author (Cinat|@em.uni-frankfurt.de).

\section{Ethics}

All animal procedures were performed according to the guidelines of the Canadian Council on Animal Care and approved by the Institutional Review Board of the University of British Columbia (approval \#A10-0295).

Received: 29 March 2016 Accepted: 20 September 2016 Published online: 27 September 2016

\section{References}

1. Pectasides D, Pectasides M, Economopoulos T. Systemic chemotherapy in locally advanced and/or metastatic bladder cancer. Cancer Treat Rev. 2006;32(6):456-70.

2. von der Maase H, Sengelov L, Roberts JT, Ricci S, Dogliotti L, Oliver T, Moore MJ, Zimmermann A, Arning M. Long-term survival results of a randomized trial comparing gemcitabine plus cisplatin, with methotrexate, vinblastine, doxorubicin, plus cisplatin in patients with bladder cancer. J Clin Oncol. 2005;23(21):4602-8.

3. Sonpavde G, Galsky MD, Hutson TE. Current optimal chemotherapy for advanced urothelial cancer. Expert Rev Anticancer Ther. 2008;8(1):51-61.

4. Choueiri TK, Ross RW, Jacobus S, Vaishampayan U, Yu EY, Quinn DI, Hahn NM, Hutson TE, Sonpavde G, Morrissey SC, et al. Double-blind, randomized trial of docetaxel plus vandetanib versus docetaxel plus placebo in platinum-pretreated metastatic urothelial cancer. J Clin Oncol. 2012;30(5):507-12.

5. Irby RB, Yeatman TJ. Role of Src expression and activation in human cancer. Oncogene. 2000;19(49):5636-42.

6. Boyer B, Bourgeois Y, Poupon MF. Src kinase contributes to the metastatic spread of carcinoma cells. Oncogene. 2002;21(15):2347-56.

7. Yu EY, Duan F, Muzi M, Deng X, Chin BB, Alumkal JJ, Taplin ME, Taub JM, Her man B, Higano CS, et al. Castration-resistant prostate cancer bone metastasis response measured by $18 \mathrm{~F}$-fluoride PET after treatment with dasatinib and correlation with progression-free survival: results from American College of Radiology Imaging Network 6687. J Nucl Med. 2015;56(3):354-60.

8. Gold KA, Lee JJ, Harun N, Tang X, Price J, Kawedia JD, Tran HT, Erasmus $J$ J, Blumenschein GR, William WN, et al. A phase I/II study combining erlotinib and dasatinib for non-small cell lung cancer. Oncologist. 2014;19(10):1040-1.

9. Levitt JM, Yamashita H, Jian W, Lerner SP, Sonpavde G. Dasatinib is preclinically active against Src-overexpressing human transitional cell carcinoma of the urothelium with activated Src signaling. Mol Cancer Ther. 2010;9(5):1128-35

10. Saini S, Arora S, Majid S, Shahryari V, Chen Y, Deng G, Yamamura S, Ueno K, Dahiya R. Curcumin modulates microRNA-203-mediated regulation of the Src-Akt axis in bladder cancer. Cancer Prev Res (Phila). 2011;4(10):1698-709.
11. Wu Y, Moissoglu K, Wang H, Wang X, Frierson HF, Schwartz MA, Theodorescu D. Src phosphorylation of RhoGDI2 regulates its metastasis suppressor function. Proc Natl Acad Sci USA. 2009;106(14):5807-12.

12. Thomas S, Overdevest JB, Nitz MD, Williams PD, Owens CR, SanchezCarbayo M, Frierson HF, Schwartz MA, Theodorescu D. Src and caveolin-1 reciprocally regulate metastasis via a common downstream signaling pathway in bladder cancer. Cancer Res. 2011;71(3):832-41.

13. Hahn NM, Knudsen BS, Daneshmand S, Koch MO, Bihrle R, Foster RS, Gardner TA, Cheng L, Liu Z, Breen T, et al. Neoadjuvant dasatinib for muscle-invasive bladder cancer with tissue analysis of biologic activity. Urol Oncol. 2016:34(1):4.e11-7.

14. Vallo S, Michaelis M, Rothweiler R, Bartsch G, Gust KM, Limbart DM, Rödel F, Wezel F, Haferkamp A, Cinatl J Jr. Drug-resistant urothelial cancer cell lines display diverse sensitivity profiles to potential second line therapeutics. Transl Oncol. 2015;8(3):210-6.

15. Gust KM, McConkey DJ, Awrey S, Hegarty PK, Qing J, Bondaruk J, Ashkenazi A, Czerniak B, Dinney CP, Black PC. Fibroblast growth factor receptor 3 is a rational therapeutic target in bladder cancer. Mol Cancer Ther. 2013;12(7):1245-54

16. Michaelis M, Rothweiler F, Barth S, Cinatl J, van Rikxoort M, Löschmann N, Voges Y, Breitling R, von Deimling A, Rödel F, et al. Adaptation of cancer cells from different entities to the MDM2 inhibitor nutlin-3 results in the emergence of p53-mutated multi-drug-resistant cancer cells. Cell Death Dis. 2011;2:e243.

17. Rutigliano L, Corradetti B, Valentini L, Bizzaro D, Meucci A, Cremonesi F, Lange-Consiglio A. Molecular characterization and in vitro differentiation of feline progenitor-like amniotic epithelial cells. Stem Cell Res Ther. 2013;4(5):133.

18. Black PC, Shetty A, Brown GA, Esparza-Coss E, Metwalli AR, Agarwal PK, McConkey DJ, Hazle JD, Dinney CP. Validating bladder cancer xenograft bioluminescence with magnetic resonance imaging: the significance of hypoxia and necrosis. BJU Int. 2010;106(11):1799-804.

19. Hadaschik BA, Black PC, Sea JC, Metwalli AR, Fazli L, Dinney CP, Gleave ME, So Al. A validated mouse model for orthotopic bladder cancer using transurethral tumour inoculation and bioluminescence imaging. BJU Int. 2007;100(6):1377-84

20. Wie SM, Adwan TS, DeGregori J, Anderson SM, Reyland ME. Inhibiting tyrosine phosphorylation of protein kinase $C \delta(P K C \delta)$ protects the salivary gland from radiation damage. J Biol Chem. 2014;289(15):10900-8.

21. Dinney CP, Fishbeck R, Singh RK, Eve B, Pathak S, Brown N, Xie B, Fan D, Bucana CD, Fidler IJ. Isolation and characterization of metastatic variants from human transitional cell carcinoma passaged by orthotopic implantation in athymic nude mice. J Urol. 1995;154:1532-8.

22. Bai Y, Kim JY, Watters JM, Fang B, Kinose F, Song L, Koomen JM, Teer JK, Fisher K, Chen YA, et al. Adaptive responses to dasatinib-treated lung squamous cell cancer cells harboring DDR2 mutations. Cancer Res. 2014;74(24):7217-28.

23. Hurst RE, Hauser PJ, Kyker KD, Heinlen JE, Hodde JP, Hiles MC, Hurst RE, Kosanke SD, Dozmorov M, Ihnat MA. Suppression and activation of the malignant phenotype by extracellular matrix in xenograft models of bladder cancer: a model for tumor cell "dormancy". PLOS ONE. 2013:8(5):e64181.

24. Chopra A, Murray ME, Byfield FJ, Mendez MG, Halleluyan R, Restle DJ, Raz-Ben Aroush D, Galie PA, Pogoda K, et al. Augmentation of integrinmediated mechanotransduction by hyaluronic acid. Biomaterials. 2013;35(1):71-82

25. Pichot CS, Hartig SM, Xia L, Arvanitis C, Monisvais D, Lee FY, Frost JA, Corey SJ. Dasatinib synergizes with doxorubicin to block growth, migration, and invasion of breast cancer cells. Br J Cancer. 2009;101(1):38-47.

26. Li YJ, He YF, Han XH, Hu B. Dasatinib suppresses invasion and induces apoptosis in nasopharyngeal carcinoma. Int J Clin Exp Pathol. 2015;8(7):7818-24.

27. McCaig AM, Cosimo E, Leach MT, Michie AM. Dasatinib inhibits CXCR4 signaling in chronic lymphocytic leukaemia cells and impairs migration towards CXCL12. PLoS ONE. 2012;7(11):e48929.

28. Buettner R, Mesa T, Vultur A, Lee F, Jove R. Inhibition of Src family kinases with dasatinib blocks migration and invasion of human melanoma cells. Mol Cancer Res. 2008;6(11):1766-74. 